\title{
Effect of Nonlinear Functions on Prediction of the Creep Behavior in Fibrous Composites Theoretically
}

\author{
V. MONFARED \\ Young Researchers and Elite Club, Zanjan Branch, Islamic Azad University, Zanjan, Iran, \\ E-mail:vahid_monfared_57@yahoo.com \\ cross $^{\text {ref }}$ http://dx.doi.org/10.5755/j01.mech.24.2.19535
}

\section{Introduction}

Creep phenomenon may be hazardous for mechanical and electromechanical composites, connections, networks and devices. Recently, the metal matrix composites (MMC's) are generally employed to design the mechanical systems and devices due to their advantages. Therefore, analysis of the creep behavior is essential and significant for safe designing the fibrous composite devices. Different theoretical method is presented for analyzing the second stage creep of the short fiber composites subjected to axial load using nonlinear displacement functions. Behavior of crept matrix is described by an exponential creep law, whilst the fibers behave elastically in general. The major plan of this research work is prediction of the creeping response and behavior in the fibrous composites for preventing unwanted events, over and above, controlling the creep deformation rate theoretically and numerically. Newly, the creep analysis of the fibrous composites is one of the important challenges in various applied sciences and technologies. MMC's contain a lot of advantages such as excellent conductivities. Using the short fiber composites is recently growing because of their applications in different industries. The elevated temperature creep behavior of $\mathrm{SiC}$ short fibers reinforced $\mathrm{Al}$ alloys is the significant topic of investigations that intended at analyzing the ability of the mentioned composites for using as reinforced materials at the elevated temperature applications [1-10]. So, analysis of the crept reinforced materials behavior is significant and fundamental, because, the happening of the creep in the reinforced materials can be risky. So, the plasticity and creep investigation is more important in the various industries. Numerous investigators have analyzed the creep behavior in view of the diverse approaches [1-3].

The model of Shear-Lag usable to irregular fibrous composites has been introduced [4-8]. For example, Cox [4] proposed a stress transfer method in the unidirectional long or short fiber composites, which is known as the shear lag theory. The creep of dispersion reinforced aluminum based metal matrix composite has been experimentally analyzed $[9,10]$. The second stage creep of $\mathrm{SiC} / \mathrm{Al}$ composite at $573 \mathrm{~K}$ was experimentally studied [9].

Moreover, analysis of the creep deformation in non-reinforced regions of crept short fiber composites has been done under tensile load using the imaginary fiber technique [11]. In the recent years, the theoretical methods have been introduced for analyzing nonlinear differential and ordinary equations with purpose of obtaining suitable solutions and algorithms. Additionally, some analytical and experimental attempts were performed to study the creep be- haviors [12-14].

Also, recently interesting research work has been done about creep in the optoelectronic short fiber composites by different approaches [15].

In addition, interesting and applied research works were done by various investigators about creep analysis [1620]. For example, a study has been carried out regarding the simulation method of linear creep parameters of laminated composites when the composite was loaded along the joint of the layers. In which, the developed method was based on the numerical integration of the second kind Volterra integral equation taking out the stress mean before the integral [16].

This paper tries to present a comprehensive study on the second stage creep of the short fiber composite in order for predicting and analyzing the creep behavior using nonlinear displacement functions theoretically and numerically.

\section{Materials and methods}

Here, a unit cell model as axisymmetric (representative of a complete short fiber composite) is assumed to simulate the creep of fibrous composite shown in Fig. 1.

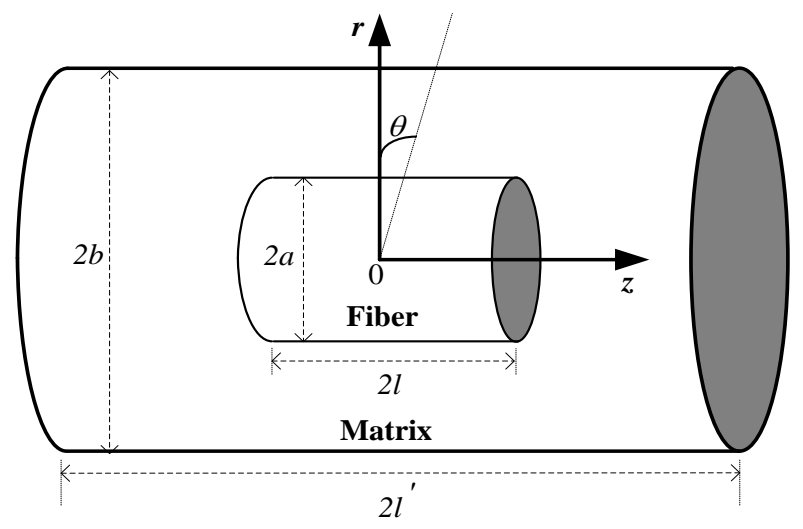

Fig. 1 Unit cell model

It is supposed that a cylindrical fiber with a radius $a$ and a length $2 l$ is inserted in a coaxial cylindrical matrix with an outer radius $b$ and a length $2 l^{\prime}$. The volume fraction and aspect ratio of the fiber are presented by $f$ and $s=l / a$ respectively. Additionally, $k=l^{\prime} a / l b$ is considered as a parameter in relation with the geometry of the unit cell. An applied axial tensile loading $\sigma_{0}$, is uniformly applied on the end faces of the unit cell (at $z= \pm l^{\prime}$ ). The creep behavior of the matrix is introduced by an exponential function as the following in Eq. (1): 


$$
\dot{\varepsilon}_{e}=A \exp \left(\frac{\sigma_{e}}{B}\right)
$$

where $A$ and $B$ are the creep constants of the crept matrix material, and also the equivalent stress $\sigma_{e}$ and the equivalent strain rate $\dot{\varepsilon}_{e}$ have been introduced in Eq. (1). The generalized constitutive equations for the creep of the matrix are considered as below:

$$
\begin{aligned}
& \dot{\varepsilon}_{r}=\frac{\partial \dot{u}}{\partial r}=\frac{\dot{\varepsilon}_{e}}{\sigma_{e}}\left[\sigma_{r}-\frac{1}{2}\left(\sigma_{\theta}+\sigma_{z}\right)\right], \\
& \dot{\varepsilon}_{\theta}=\frac{\dot{u}}{r}=\frac{\dot{\varepsilon}_{e}}{\sigma_{e}}\left[\sigma_{\theta}-\frac{1}{2}\left(\sigma_{r}+\sigma_{z}\right)\right], \\
& \dot{\varepsilon}_{z}=\frac{\partial \dot{w}}{\partial z}=\frac{\dot{\varepsilon}_{e}}{\sigma_{e}}\left[\sigma_{z}-\frac{1}{2}\left(\sigma_{r}+\sigma_{\theta}\right)\right], \\
& \dot{\gamma}_{r z}=\frac{\partial \dot{u}}{\partial z}+\frac{\partial \dot{w}}{\partial r}=3 \frac{\dot{\varepsilon}_{e}}{\sigma_{e}} \tau_{r z}=2 \dot{\varepsilon}_{r z} .
\end{aligned}
$$

In addition, the incompressibility relation must be satisfied, that is:

$$
\frac{\partial \dot{u}}{\partial r}+\frac{\dot{u}}{r}+\frac{\partial \dot{w}}{\partial z}=0
$$

Parameters of $\dot{u}$ and $\dot{w}$ are radial and axial displacement rates respectively. In addition, the equivalent stress $\sigma_{e}$ and equivalent strain rate $\dot{\varepsilon}_{e}$ are given by:

$$
\begin{aligned}
& \sigma_{e}=\frac{\sqrt{2}}{2} \sqrt{6 \tau_{r z}^{2}+\left(\sigma_{r}-\sigma_{\theta}\right)^{2}+\left(\sigma_{r}-\sigma_{z}\right)^{2}+\left(\sigma_{z}-\sigma_{\theta}\right)^{2}}, \\
& \dot{\varepsilon}_{e}=\frac{\sqrt{2}}{3} \sqrt{6 \dot{\varepsilon}_{r z}^{2}+\left(\dot{\varepsilon}_{r}-\dot{\varepsilon}_{\theta}\right)^{2}+\left(\dot{\varepsilon}_{r}-\dot{\varepsilon}_{z}\right)^{2}+\left(\dot{\varepsilon}_{z}-\dot{\varepsilon}_{\theta}\right)^{2}} .
\end{aligned}
$$

The equilibrium equations for the axisymmetric problem considering the cylindrical coordinates $(r, \theta, z)$ are given as the following forms:

$$
\begin{aligned}
& \frac{\partial \sigma_{z}}{\partial z}+\frac{\partial \tau_{r z}}{\partial r}+\frac{\tau_{r z}}{r}=0, \\
& \frac{\partial \sigma_{r}}{\partial r}+\frac{\partial \tau_{r z}}{\partial z}+\frac{\sigma_{r}-\sigma_{\theta}}{r}=0 .
\end{aligned}
$$

At which, the parameters of $\dot{\varepsilon}_{r}, \dot{\varepsilon}_{\theta}, \dot{\varepsilon}_{z}$ and $\dot{\varepsilon}_{r z}$ are the strain rate components in the directions indicated by subscripts. Moreover the parameters of $\sigma_{r}, \sigma_{\theta}, \sigma_{z}$ and $\tau_{r z}$ are the radial, circumferential, axial, and shear stress components, respectively.

\section{Boundary conditions}

For obtaining the steady state creep behavior, the following boundary conditions (BC's) are given as the following:

$$
\begin{aligned}
& \left.\dot{w}(a, z)\right|_{0 \leq z \leq l}=0, \\
& \left.\dot{u}(b, z)\right|_{0 \leq z \leq l}=\dot{u}_{b}, \\
& \left.\tau_{r z}(b, z)\right|_{0 \leq z \leq l}=0, \\
& \left.\dot{\gamma}_{r z}(b, z)\right|_{0 \leq z \leq l}=0, \\
& \dot{w}(b, l)=\frac{2 l \dot{u}_{b}}{b}, \\
& \left.\dot{u}(a, z)\right|_{0 \leq z \leq l}=0, \\
& \left.\dot{\gamma}_{r z}(b, z)\right|_{l \leq z \leq l^{\prime}}=0, \\
& \left.\sigma_{z}\left(r, l^{\prime}\right)\right|_{0 \leq r \leq b}=\sigma_{0},
\end{aligned}
$$

Based on equilibrium equation for axial force at the $z$ direction, we have:

$$
b^{2} \sigma_{0}=a^{2} \bar{\sigma}_{z}^{f}+\left(b^{2}-a^{2}\right) \bar{\sigma}_{z}^{m}
$$

Where the superscripts $m$ and $f$ indicate the crept matrix and elastic fiber and the bar sign on the stress symbol $\left(\bar{\sigma}_{z}^{m}\right)$ denotes the average value over the cross sections of the matrix and fiber. It should be noted that all results are in relation with the crept matrix in the second stage creep of the short fiber composites.

Absence and presence of the superscript $m$ indicate that mentioned parameter is related to the matrix, but presence of the superscript $f$ is necessary for indicating the fiber. For instance, $\bar{\sigma}_{z}^{m} \cong \bar{\sigma}_{z}, \dot{u}(r, z) \cong \dot{u}^{m}(r, z)$. secondary and primary edges of the unit cell are depicted in Fig. 2 in the second stage creep subjected to tensile axial stress [19].

The radial and axial displacement rates $\dot{u}$ and $\dot{w}$ are determined by means of the incompressibility and appropriate boundary conditions (BC's). Then, stress fields are predicted employing the constitutive and equilibrium equations considering incompressibility, boundary conditions and geometric relations (Eqs. (1-12)). The nonlinear function of $\dot{u}(r, z)$ is given as the following:

$$
\dot{u}(r, z)=\sum_{j=20}^{24} k_{j-19} r^{j} .
$$

Therefore, the axial displacement rate $\dot{w}(r, z)$ is achieved by the incompressibility condition as follows:

$$
\dot{w}(r, z)=-\left[\sum_{j=20}^{24} k_{j-19} r^{j-1}(1+j)\right] z .
$$

Here, the unknown coefficients of $k_{j}$ 's are also obtained by boundary conditions presented in Eqs. (8a-h). 
The shear stress in the crept matrix is determined by Eqs. (1-5), that is:

$$
\tau_{r z}^{m}=\frac{B \ln \left(\frac{\dot{\varepsilon}_{e}}{A}\right) \dot{\gamma}_{r z}}{3 \dot{\varepsilon}_{e}} .
$$

For simplifying the computations, the value of $\dot{u}_{b}$ is obtained by reference of [9]. Stresses in the matrix, $\sigma_{z}^{m}, \sigma_{r}^{m}$ and $\sigma_{\theta}^{m}$ are obtained by solving the equilibrium and constitutive equations considering geometry relations simultaneously (Eqs. (1-12)).

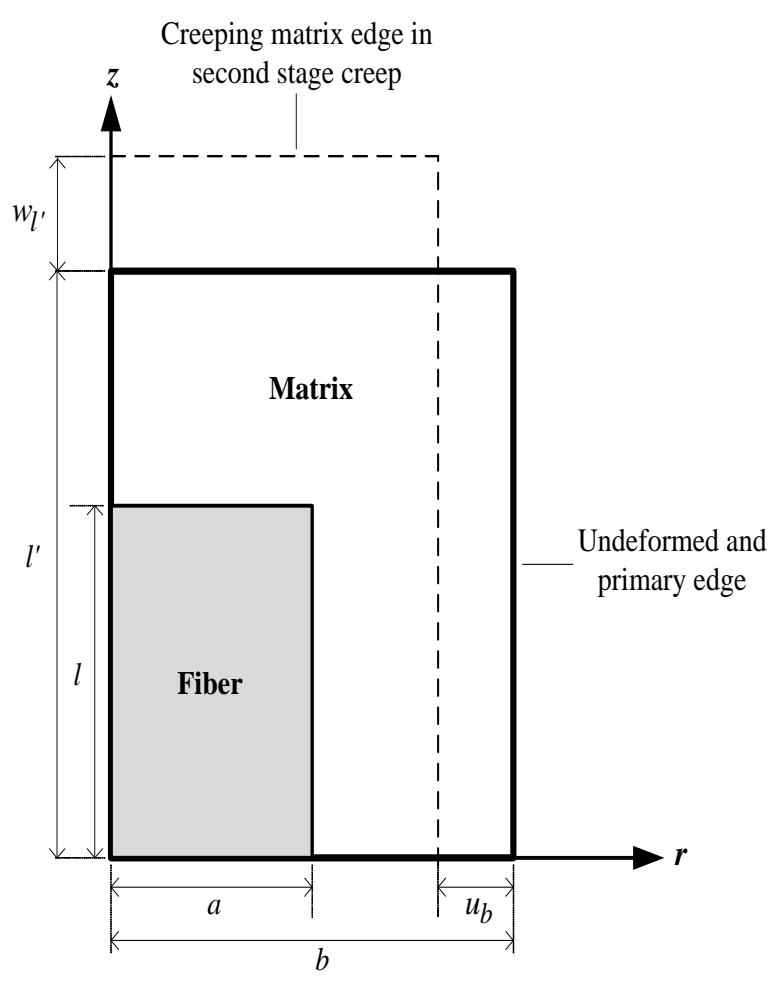

Fig. 2 Primary and secondary edges (front view)

\section{Results and discussions}

For investigating the confirmation of the current theoretical method, the SiC/Al6061 composite is selected as a investigation case. Finite element calculations are done employing the FE commercial code of ANSYS. The model geometry is chosen as shown in Fig. 1, and the surface conditions are applied as presented in Eqs. (8a-h).

Also, the axisymmetric nonlinear quadratic element of PLANE 183 is used for FEM analysis. For the composite used here (SiC/A16061), the volume fraction of fibers is $15 \%$ and the fibers have an aspect ratio of $7.4(s=7.4)$ and $k=0.76$, which are in accordance with the suggestions made by Morimoto et al. [9]. Furthermore, the second stage creep constants of the matrix material, $A$ and $B$, in Eq. (1) are considered as $A=\exp (-24.7)$ and $B=6.47$, which have been given by Morimoto et al. [9]. The applied load and temperature are considered as $\sigma_{0}=\sigma_{a p p}=80 \mathrm{MPa}$ and $\mathrm{T}=573 \mathrm{~K}$ respectively. Tables 1-3 show the creep behavior of the short fiber composite by obtained values of stresses at $r=b-\kappa(\kappa$ is a positive value and small enough).
Table 1

Comparison among the shear, equivalent, axial, radial and circumferential values using the analytical and FE methods

\begin{tabular}{|l|c|c|c|}
\multirow{2}{*}{\multicolumn{1}{|c}{$\begin{array}{c}\text { Stresses in } \\
\text { matrix (MPa) }\end{array}$}} & \multicolumn{3}{c|}{$\begin{array}{c}\text { Normalized axial } \\
\text { Position }(z / l) \text { at } \\
r=b-\kappa\end{array}$} \\
\cline { 2 - 4 } & 0 & 0.5 & 1 \\
\hline Shear stress (new work) & $10^{-5}$ & $10^{-5}$ & $10^{-5}$ \\
\hline Equivalent stress (new work) & 28.8 & 28.8 & 28.8 \\
\hline Shear stress (FEM) & $10^{-5}$ & $10^{-5}$ & $10^{-5}$ \\
\hline Equivalent stress (FEM) & 30 & 29.7 & 29.5 \\
\hline Axial stress (analytical, new work) & -61.2 & -1.3 & 52 \\
\hline Axial stress (FEM) & -59.4 & -0.8 & 50.4 \\
\hline $\begin{array}{l}\text { Radial stress (analytical, new } \\
\text { work) }\end{array}$ & -95 & -33.5 & 46 \\
\hline Radial stress (FEM) & -95.2 & -34.1 & 46.2 \\
\hline $\begin{array}{l}\text { Circumferential stress (analytical, } \\
\text { new work) }\end{array}$ & -86 & -26 & 26 \\
\hline Circumferential stress (FEM) & -85.5 & -27.2 & 26 \\
\hline
\end{tabular}

According to Tables 1-3, suitable agreements are found. Founded on the computed results, great and increasing gradients and slopes are found at the shear stress at the interface and equivalent stress behaviors at the central locations of the elastic fiber.

Table 2

Comparison between the shear and equivalent results using the analytical and FE methods at $r=a+\kappa$

\begin{tabular}{|l|l|c|c|c|c|}
\hline \multirow{2}{*}{ Methods } & \multirow{2}{*}{$\begin{array}{c}\text { Stresses in } \\
\text { matrix (MPa) }\end{array}$} & \multicolumn{4}{|c|}{$\begin{array}{c}\text { Normalized axial } \\
\text { position }(z / l) \text { at } r=a+\kappa\end{array}$} \\
\cline { 3 - 6 } & & 0 & 0.1 & 0.5 & 1 \\
\hline \multirow{2}{*}{ New work } & Shear stress & 0 & 19.2 & 28.4 & 29 \\
\cline { 2 - 6 } & Equivalent stress & 0 & 32.6 & 47.8 & 52.7 \\
\hline \multirow{2}{*}{ FEM } & Shear stress & 0 & 20.1 & 25.6 & 30.5 \\
\cline { 2 - 6 } & Equivalent stress & 0 & 33.1 & 47 & 53.1 \\
\hline
\end{tabular}

Table 3

Comparison among the axial, radial and circumferential values using the analytical and FE methods at $r=a+\kappa$

\begin{tabular}{|c|c|c|c|}
\hline \multirow{2}{*}{$\begin{array}{c}\text { Stresses in } \\
\text { matrix (MPa) }\end{array}$} & \multicolumn{3}{|c|}{$\begin{array}{c}\text { Normalized axial } \\
\text { position }(z /) \text { at } r=a+\kappa\end{array}$} \\
\cline { 2 - 4 } & 0 & 0.5 & 1 \\
\hline $\begin{array}{c}\text { Axial, Circumferential and } \\
\text { Radial stresses (New work) }\end{array}$ & -90.1 & -37.4 & 25.7 \\
\hline $\begin{array}{c}\text { Axial, Circumferential and } \\
\text { Radial stresses (FEM) }\end{array}$ & -89.8 & -37 & -379.1 \\
\hline
\end{tabular}

However, small slopes and gradients are seen for the shear (at the interface) and equivalent stress behaviors at the end of the elastic fiber clearly. In addition, the changes of the gradients at the interface are owing to changes of the geometric factors, material properties, and applied stress and load. However, linear behaviors are considered in the axial, radial and circumferential stress components at the interface and outer surface of the unit cell. In addition, changes in gradient of the axial, radial and circumferential stresses are flat and consistent. According to the computed and obtained results, the interfacial shear and equivalent stresses have logarithmic and non-linear behaviors whilst the axial, radial and circumferential stress behaviors are linear at the interface. Interestingly, excellent compatibilities are found between the analytical and numerical results. Figs. 3-5 prove and show the finite element (FE) solution of 
the crept short fiber composite. Fig. 3 shows contour plot and nodal solution of the crept short fiber composite. In accordance with Fig. 3, the significant locations are obtained and predicted.

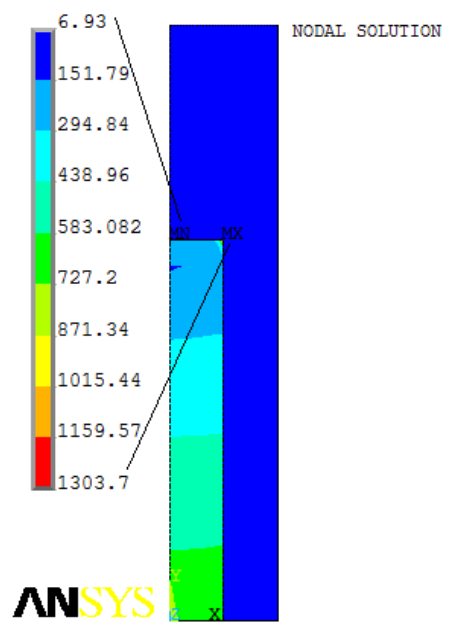

Fig. 3 Nodal solution (Presentation of the critical regions: MX, MN)

Fig. 4 schematically reports the equivalent stress behavior of the creeping short fiber composite that is logarithmic with variable gradients (at the interface). Also, Fig. 5 explains that the equivalent stress behavior of the creeping short fiber composite at the outer surface is approximately invariable with consistent gradients. The mentioned behaviors show that these behaviors are controllable.

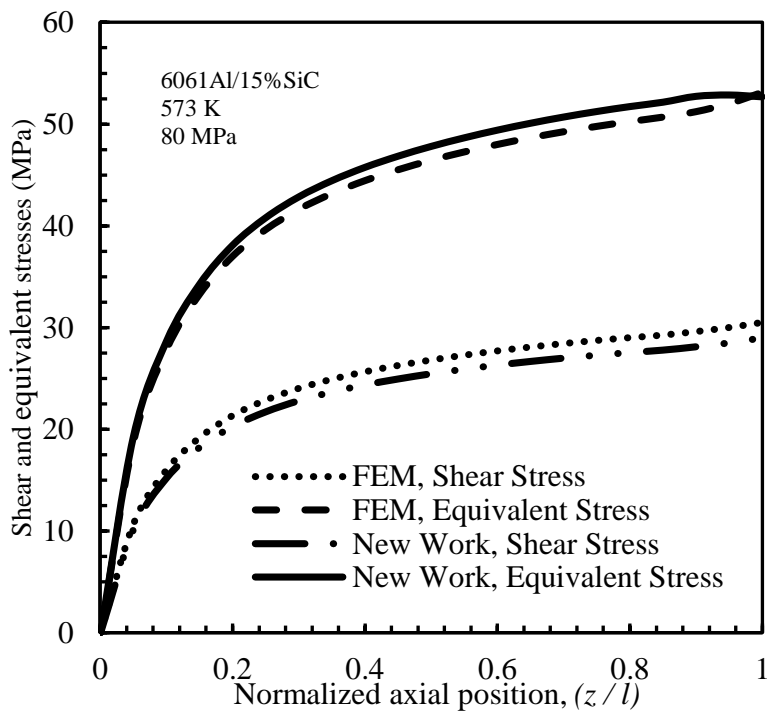

Fig. 4 Comparing the FEM and analytical method results for predicting the equivalent and shear stress behaviors at $r=a+\kappa$

Equivalent and shear stresses at the outer surface and interface (i.e. at $r=a+\kappa, b-\kappa)$ were graphically presented in Figs. $(4,5)$. As seen, both the present theoretical and FE methods show a logarithmic behavior for interfacial equivalent stress. In addition, the results show that the interfacial equivalent stress gradients are very large near the center of the elastic fiber. However, these gradients are small in the other regions of the fiber.

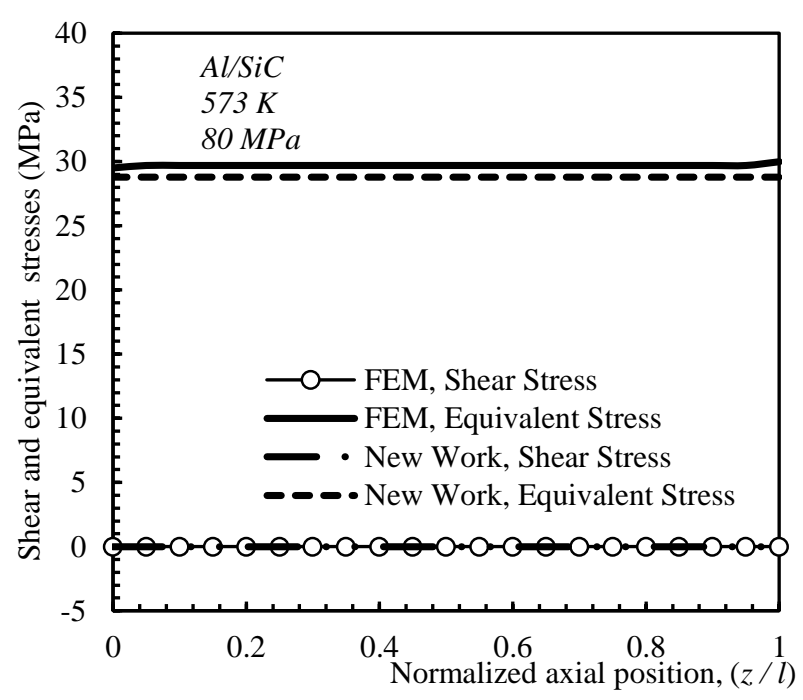

Fig. 5 Comparison of FEM and analytical method results to predict the equivalent stress behavior at $r=b-\kappa$

Table 4

Comparing among the present theoretical method, FEM results, and experimental data [9] for obtaining the composite creep strain rate $(1 / \mathrm{s})$

\begin{tabular}{|c|c|c|c|}
\hline $\begin{array}{c}\text { Stress } \\
(\mathrm{MPa})\end{array}$ & $\begin{array}{c}\text { Theoretical } \\
\text { method, } \\
\text { (New work) }\end{array}$ & FEM & $\begin{array}{c}\text { Experimental } \\
{[9]}\end{array}$ \\
\hline 80 & $1.45 \times 10^{-9}$ & $1.19 \times 10^{-9}$ & $6.67 \times 10^{-8}$ \\
\hline 60 & $3.73 \times 10^{-10}$ & $2.93 \times 10^{-10}$ & $7.38 \times 10^{-10}$ \\
\hline
\end{tabular}

According to Table 4, the composite creep strain rates determined by the present theoretical method, FEM, and the experimental methods have been compared. The obtained results present a suitable and good agreement among the values of theoretical method, FEM, and experimental data. Also, it is concluded that the equivalent and shear stress behaviors are similar to function behavior of $f(x)=$ $=\left.A_{0} \sqrt{A_{1} x}\right|_{0} ^{z / l}$. That is, the equivalent and shear stress behaviors are similar to the function behavior of $\left.A_{0} \sqrt{A_{1} x}\right|_{0} ^{z / l}$ approximately.

\section{Conclusions}

A new theoretical approach is proposed to study the second stage creep in the short fiber composites subjected to the axial load based on nonlinear functions with application in the fibrous composites. Accuracy of the obtained theoretical results is suitable. The good accuracy is due to employing the nonlinear high order displacement functions and basic and constitutive equations. Also, as an important and interesting result and conclusion, it is concluded that the equivalent and shear stress behaviors and trends are close to function behavior of $f(x)=\left.A_{0} \sqrt{A_{1} x}\right|_{0} ^{z / l}$ mathematically. The present formulation (Eqs. $(10,11))$ can be applied and used in the elasticity and plasticity problems based on well-behaved functions. These two important functions have been determined by MATLAB program and codes.

Therefore, we can employ the mentioned approach to predict the creep behavior of the fibrous composites to 
prevent undesired and unsafe events, as well as, control of creep deformation rate theoretically. Significant gradient changes are found in the shear and equivalent stress behaviors that are due to the nature of the creep parameters. Moreover, the interfacial shear and equivalent stress behaviors are the same with logarithmic functions; linear behavior is seen in the axial, radial and circumferential stresses at the interface and outer surface of the creeping unit cell. The smooth gradients are considered in the axial, radial and circumferential stress behaviors. The major advantage of the presented model is its capability in prediction of the stress fields, displacement and strain rate component behaviors. The present theoretical method is also comprehensive and easy owing to proposing the accurate displacement rate fields. Lastly, the present theoretical model may be employed in different scientific engineering problems in the applied physics and mechanics like elastic and plastic analysis of nano-composites and related engineering fields. It should be mentioned that the present model is simpler than the other available models.

\section{References}

1. Nixon, R.D.; Koester, D.A.; Chevacharoenkul, S.; Davis, R.F. 1990. Steady-state creep of hot-pressed SiC whisker-reinforced silicon nitride, Composites Science and Technology 37 (1-3): 313-328. http://dx.doi.org/10.1016/0266-3538(90)90107-G.

2. Lee, Y.S.; Batt, T.J.; Liaw, P.K. 1990. Stress analysis of a composite material with short elastic fibre in power law creep matrix, International Journal of Mechanical Sciences 32(10): 801-815. http://dx.doi.org/10.1016/0020-7403(90)90160-K.

3. Nayfeh, A.H.; Abdelrahman, W.G. 1998. Micromechanical modeling of load transfer in fibrous composites, Mechanics of Materials 30: 307-324. http://dx.doi.org/10.1016/S0167-6636(98)00038-6.

4. Cox, H.L. 1952. The elasticity and strength of paper and other fibrous materials, British Journal of Applied Physics 3: 72-79.

http://dx.doi.org/10.1088/0508-3443/3/3/302.

5. Mileiko, S.T. 1970. Steady state creep of a composite with short fibres, Journal of Material. Sciences 5: 254261. http://dx.doi.org/10.1007/BF00551002.

6. Fukuda, H.; Chou, T.W. 1981. An advanced shear-lag model applicable to discontinuous fiber composites, Journal of Composite Materials 1(15): 79-91. http://dx.doi.org/ 10.1177/002199838101500107.

7. McLean, M. 1985. Creep deformation of metal-matrix composites, Composite Science and Technology 23: 3752. http://dx.doi.org/10.1016/0266-3538(85)90010-7.

8. Zhang, J. 2003. Modeling of the influence of fibers on creep of fiber reinforced cementitious composite, Composite Science and Technology 63(13):1877-1884. http://dx.doi.org/10.1016/S0266-3538(03)00160-X.

9. Morimoto, T.; Yamaoka, T.; Lilholt, H.; Taya, M. 1988. Second stage creep of silicon carbide whisker/6061 aluminum composite at $573 \mathrm{~K}$, Journal of Engineering and Material Technology 110:70-76. http://dx.doi.org/10.1115/1.3226032.
10. Xianglong, G.; Weijie, L.; Liqiang, W.; Jining, Q. 2014. A research on the creep properties of titanium matrix composites rolled with different deformation degrees, Materials and Design 63:50-55. http://dx.doi.org/10.1016/j.matdes.2014.05.063.

11. Monfared, V.; Daneshmand, S.; Reddy, J.N. 2015. Rate dependent plastic deformation analysis of short fiber composites employing virtual fiber method, Journal of Computational Sciences 10: 26-35. http://dx.doi.org/10.1016/j.jocs.2015.05.007.

12. Tapkın, S.; Çevik, A.; Uşara, U.; Gülşan, E. 2013. Rutting prediction of asphalt mixtures modified by polypropylene fibers via repeated creep testing by utilising genetic programming, Materials Research 16(2):277292. http://dx.doi.org/10.1590/S1516-14392013005000012.

13. Reis, J.F.S.; Bueno, L.O. 2014. Hot tensile and creep rupture data extrapolation on $2.25 \mathrm{Cr}-1 \mathrm{Mo}$ steel using the CDM penny-kachanov methodology, Materials Research 17(2):518-526. http://dx.doi.org/10.1590/S1516-14392014005000007.

14. Costa, P.R. J.; Moura, C. N.; Wade, D.A. 2014. Evaluation of a 7050-TAF aluminum alloy submitted to creep age forming, Materials Research 17(3):603-611. http://dx.doi.org/10.1590/S1516-14392014005000051.

15. Monfared, V.; Daneshmand, S. 2015. Energy considering for predicting the micro-creep behavior in composites with application in microelectronic and optoelectronic/photonic devices, Optoelectronics and Advanced Materials - Rapid Communications 9 (3-4):410-414. http://oam-rc.inoe.ro/download.php?idu=2546.

16. Zabulionis, D.; Gailius, A. 2007. Numerical modelling of creep functions of laminated composites, Mechanika 3(65): 5-11. http://www.mechanika.ktu.lt/index.php/Mech/article/view/14829/7679.

17. Žvinys, J.; Kandrotaitė Janutienè, R. 2008. Influence of high temperature heat treatment on creep properties of high speed steel, Mechanika 3(71): 72-75. http://www.vpa.ktu.lt/index.php/Mech/article/view/15091/7774.

18. Skindaras, R.; Valiulis, A.V.; Spychalski, W.L. 2013. The structure and mechanical properties of the high chromium and nickel content cast alloy after long duration work in high temperature, Mechanika 19(6): 706710. http://dx.doi.org/10.5755/j01.mech.19.6.5986.

19. Korobko, E.; Novikova, Z.; Zhurauski, M.; Kazak, H.; Dragašius, E. 2014. Investigation of elasticity of magnetosensitive adaptive materials for laminated composite structures, Mechanika 20 (5):466-470. http://dx.doi.org/10.5755/j01.mech.20.5.7080.

20. Monfared, V. 2017. Role of High Order Functions in Analysis of the Creep Behavior of a Short Fiber Composite "Silicon Carbide/Aluminum 6061", Silicon 9: 339345. https://doi.org/10.1007/s12633-016-9502-0. 
V. Monfared

\section{EFFECT OF NONLINEAR FUNCTIONS ON PREDICTION OF THE CREEP BEHAVIOR IN FIBROUS COMPOSITES THEORETICALLY}

S u m mary

This paper presents the analysis of the creep behavior for safe designing the fibrous composite devices. Special theoretical method is presented for analyzing the second stage creep of the short fiber composites subjected to axial load using nonlinear displacement functions. Behavior of creeping matrix is described by an exponential creep law, whilst the fibers behave elastically in general. The major plan of the present research work is prediction of the creep behavior in the fibrous composites for preventing unwanted events, over and above, controlling the creep deformation rate theoretically and numerically. Finally, good compatibilities are seen between finite element method and present theoretical method results. As an important result and finding, in general, the mentioned behaviors are ascending along with soft gradients, and so they are controllable and desired.

Keywords: creep, composite, nonlinear displacement function.

Received September 10, 2016 Accepted April 18, 2018 